\title{
Alternative splicing of CD44 mRNA by ESRP1 enhances lung colonization of metastatic cancer cell
}

\author{
Toshifumi Yae 1,2, Kenji Tsuchihashi', Takatsugu Ishimoto1, Takeshi Motohara', Momoko Yoshikawa', \\ Go J. Yoshida', Takeyuki Wada', Takashi Masuko ${ }^{3}$, Kaoru Mogushi ${ }^{4}$, Hiroshi Tanaka ${ }^{4}$, Tsuyoshi Osawa ${ }^{5}$, \\ Yasuharu Kanki ${ }^{5}$, Takashi Minami ${ }^{5}$, Hiroyuki Aburatani ${ }^{6}$, Mitsuyo Ohmura7, Akiko Kubo ${ }^{7}$, Makoto Suematsu $^{7,8}$, \\ Kazuhisa Takahashi², Hideyuki Saya ${ }^{1,9} \&$ Osamu Nagano $^{1}$
}

In cancer metastasis, various environmental stressors attack the disseminating cells. The successful colonization of cancer cells in secondary sites therefore requires the ability of the cells to avoid the consequences of such exposure to the stressors. Here we show that orthotopic transplantation of a CD44 variant isoform-expressing $\left(C D 44 v^{+}\right)$subpopulation of $4 \mathrm{~T} 1$ breast cancer cells, but not that of a $\mathrm{CD} 44 \mathrm{v}^{-}$subpopulation, in mice results in efficient lung metastasis accompanied by expansion of stem-like cancer cells. Such metastasis is dependent on the activity of the cystine transporter $\mathrm{xCT}$, and the stability of this protein is controlled by CD44v. We find that epithelial splicing regulatory protein 1 regulates the expression of CD44v, and knockdown of epithelial splicing regulatory protein 1 in $C D 44 v^{+}$cells results in an isoform switch from CD44v to CD44 standard (CD44s), leading to reduced cell surface expression of xCT and suppression of lung colonization. The epithelial splicing regulatory protein 1-CD44v$\mathrm{xCT}$ axis is thus a potential therapeutic target for the prevention of metastasis.

\footnotetext{
${ }^{1}$ Division of Gene Regulation, Institute for Advanced Medical Research, School of Medicine, Keio University, 35 Shinanomachi, Shinjuku-ku, Tokyo 160-8582, Japan. ${ }^{2}$ Department of Respiratory Medicine, Juntendo University, School of Medicine, 2-1-1 Hongo, Bunkyo-Ku, Tokyo 113-8421, Japan. ${ }^{3}$ Cell Biology Laboratory, Department of Pharmaceutical Sciences, School of Pharmacy, Kinki University, 4-1 Kowakae 3-chome, Higashiosaka-shi, Osaka 577-8502, Japan. ${ }^{4}$ Department of Bioinformatics, Division of Medical Genomics, Medical Research Institute, Tokyo Medical and Dental University 1-5-45 Yushima, Bunkyo-Ku, Tokyo 113-8510, Japan. ${ }^{5}$ Lab for Vascular Biology, RCAST, The University of Tokyo, 4-6-1 Komaba, Meguro-ku, Tokyo 153-8904, Japan. ${ }^{6}$ Genome Science Division, RCAST, The University of Tokyo, 4-6-1 Komaba, Meguro-ku, Tokyo 153-8904, Japan. ${ }^{7}$ Department of Biochemistry, School of Medicine, Keio University, 35 Shinanomachi, Shinjuku-ku, Tokyo 160-8582, Japan. ${ }^{8}$ Japan Science and Technology Agency, Exploratory Research for Advanced Technology (ERATO), Suematsu Gas Biology Project, Tokyo 102-0076, Japan. ${ }^{9}$ Japan Science and Technology Agency, Core Research for Evolutional Science and Technology (CREST), Tokyo 102-0076, Japan. Correspondence and requests for materials should be addressed to O.N. (email: osmna@sb3.so-net.ne.jp) or to H.S. (email: hsaya@a5.keio.jp).
} 
M etastasis is the major cause of death for individuals with solid tumours ${ }^{1}$, largely because of the ineffectiveness of current therapies, once metastasis is established ${ }^{2,3}$. Metastasis is an inefficient process, however, with few cells released from a primary tumour eventually reinitiating tumour growth at distant sites. The formation of metastases has therefore been thought to result from the dissemination of stem-like cancer cells and their colonization of secondary sites ${ }^{4,5}$. The cell surface protein CD44 is a major marker for stem-like cancer cells ${ }^{6-9}$ and is also highly expressed in metastatic cancer cells ${ }^{4,6}$. Although differences in CD $44^{+}$stem-like cells between primary tumours and metastases remain ill-defined, a subset of $\mathrm{CD} 44^{+}$stem-like cells in primary tumours might possess the ability to reinitiate tumour growth at distant sites ${ }^{4,6}$. It has remained largely unknown, however, whether CD44 is functionally associated with metastatic propagation by stem-like cancer cells.

CD44 has been implicated in a variety of physiological processes in addition to cancer cell invasion and metastasis ${ }^{10-13}$. CD44 exists in numerous isoforms generated through alternative messenger RNA splicing ${ }^{14}$, with variability in the extracellular domain of CD44 being thought to underlie the functional diversity of this molecule ${ }^{13,15}$. A CD44 variant $(\mathrm{CD} 44 \mathrm{v})$ isoform containing v3 (the sequence encoded by variant exon 3 ) that undergoes heparin sulphate modification has thus been shown to interact with various growth factors including heparin-binding epidermal growth factor-like growth factor and basic fibroblast growth factor ${ }^{16}$, whereas the CD44v6 isoform has been shown to act as a co-receptor for the receptor tyrosine kinase $\mathrm{c}-\mathrm{Met}^{17}$. Furthermore, we recently showed that interaction of CD44v8-10 with the cystine transporter $\mathrm{xCT}$ (SLC7A11) stabilizes the latter protein and thereby potentiates the ability of cancer cells to defend themselves against reactive oxygen species $(\mathrm{ROS})^{18}$. The generation of CD44v isoforms might therefore modulate the activity of various plasma membrane proteins including receptor tyrosine kinases and transporters in cancer cells.

Given that cancer cells are exposed to environmental stressors such as oxygen or nutrient deficiency, low $\mathrm{pH}$, inflammatory mediators, and ROS during metastasis, the ability to avoid the consequences of such exposure is required for successful colonization by cancer cells ${ }^{19-21}$. The cystine transporter $\mathrm{xCT}$ functions as a $\mathrm{Na}^{+}$-independent transporter that mediates the exchange of extracellular cystine for intracellular glutamate and thereby promotes the synthesis of reduced glutathione (GSH) ${ }^{22,23}$, a ubiquitous reducing thiol peptide that serves as an important intracellular redox buffer and is associated with resistance of cancer cells to anticancer agent ${ }^{24,25}$. The availability of cysteine is rate-limiting for GSH synthesis ${ }^{26}$, and the activity of $\mathrm{xCT}$ is therefore essential for such resistance to anticancer agents ${ }^{23,27}$. However, the functional relevance of CD44v and $\mathrm{xCT}$ in the metastatic spread of stem-like cancer cells has remained undetermined. Here we show that $\mathrm{CD} 44 \mathrm{v}-\mathrm{xCT}$ expression regulated by ESRP1 in metastatic breast cancer cells confers the ability of evasion from oxidative stress and thereby promotes the lung metastasis. These findings suggest that CD44v may be a therapeutic target.

\section{Results}

Metastatic subpopulation in 4T1 cells expresses CD44v. To investigate the role of $\mathrm{CD} 44 \mathrm{v}$ in cancer metastasis, we studied the mouse breast cancer cell line $4 \mathrm{~T} 1$ and its isogenic sublines (4T07, 168FARN, 67NR). All of these cells form primary tumours in mice, but only $4 \mathrm{~T} 1$ cells give rise to visible lung metastases ${ }^{28}$ (Fig. 1a). RT-PCR analysis revealed that the abundance of CD44v messenger RNA was markedly greater than that of CD44s mRNA in $4 \mathrm{~T} 1$ cells, whereas only CD44s mRNA was detected in the nonmetastatic sublines (Fig. 1b; Supplementary Fig. S1). Flow cytometry showed that $4 \mathrm{~T} 1$ cells consist of two subpopulations, $\mathrm{CD} 44 \mathrm{v}^{+}$cells (which predominantly express $\mathrm{CD} 44 \mathrm{v}$ ) and $\mathrm{CD}_{4} 4 \mathrm{v}^{-}$cells (which express only CD44s), whereas the nonmetastatic sublines consist only of
$\mathrm{CD} 44 \mathrm{v}^{-}$cells (Fig. 1c), suggesting that CD44v might be associated with the metastatic ability of $4 \mathrm{~T} 1$ cells. We isolated the CD44v ${ }^{+}$and $\mathrm{CD} 44 \mathrm{v}^{-}$subpopulations of $4 \mathrm{~T} 1$ cells by fluorescence-activated cell sorting (FACS) and subjected these cells to immunoblot analysis and to analysis followed by direct sequencing of the PCR products ${ }^{29}$ (Supplementary Fig. S1 and Supplementary Methods). The predominant CD44v isoform in the CD44v ${ }^{+}$cells was found to be CD44v8-10. Each subpopulation was transplanted $\left(1 \times 10^{5}\right.$ cells $)$ into mouse mammary glands. The incidence $\left(\mathrm{CD} 44 \mathrm{v}^{+}, 13 / 13\right.$; $\mathrm{CD} 44 \mathrm{v}^{-}$, 11/11) and volume (Fig. 1d) of the primary tumours derived from $\mathrm{CD} 44 \mathrm{v}^{+}$or $\mathrm{CD} 44 \mathrm{v}^{-}$cells were similar. However, the incidence of lung metastasis by $\mathrm{CD} 44 \mathrm{v}^{+}$cells was markedly higher than that of $\mathrm{CD} 44 \mathrm{v}^{-}$cells $\left(\mathrm{CD} 44 \mathrm{v}^{+}, 13 / 13 ; \mathrm{CD} 44 \mathrm{v}^{-}, 3 / 11\right)$, and both IntegriSense quantitative fluorescence imaging ${ }^{30}$ and histological analysis revealed that the extent of lung metastatic lesions derived from CD $44 \mathrm{v}^{+}$cells was greater than that of those formed by CD44v ${ }^{-}$ cells (Fig. 1e,f). The CD44v ${ }^{+}$subpopulation was thus enriched in highly metastatic cells compared with the $\mathrm{CD} 44 \mathrm{v}^{-}$subpopulation.

Given that $4 \mathrm{~T} 1$ cells are resistant to 6 -thioguanine $(6-\mathrm{TG})^{28}$, we isolated tumour cells by 6-TG selection from lung metastases formed after injection of $\mathrm{CD} 44 \mathrm{v}^{-}$cells into the tail vein. Small metastatic nodules consisted mostly of $\mathrm{CD} 44 \mathrm{v}^{-}$cells, suggesting that $\mathrm{CD} 44 \mathrm{v}^{-}$cells also possess metastasis-initiating ability (Fig. 1g). However, when $\mathrm{CD} 44 \mathrm{v}^{+}$and $\mathrm{CD} 44 \mathrm{v}^{-}$cells were injected at a 50:50 ratio, lung metastases consisted mostly of $\mathrm{CD} 44 \mathrm{v}^{+}$cells (Fig. $1 \mathrm{~g}$ ), indicating that the lung colonization potential of $\mathrm{CD} 44 \mathrm{v}^{+}$cells is much higher than that of $\mathrm{CD} 44 \mathrm{v}^{-}$cells.

ESRP1 promotes lung metastasis of $4 \mathrm{~T} 1$ cells. To identify the mechanism underlying lung colonization potential, we performed microarray analysis (Supplementary Methods) followed by gene set enrichment analysis (GSEA) ${ }^{31}$. The $\mathrm{CD} 44 \mathrm{v}^{+}$cell/CD $44 \mathrm{v}^{-}$cell gene set profile was similar to the embryonic stem (ES) cell/mouse embryonic fibroblast (MEF) and induced pluripotent stem (iPS) cell/MEF profiles (Fig. 2a). CD44v ${ }^{+}$cells thus manifest an ES celllike gene signature when compared with $\mathrm{CD} 44 \mathrm{v}^{-}$cells. The gene for epithelial splicing regulatory protein 1 (ESRP1), which regulates alternative splicing of CD $44 \mathrm{mRNA}^{14}$, was highly expressed not only in $\mathrm{CD} 44 \mathrm{v}^{+} 4 \mathrm{~T} 1$ cells but also in ES and iPS cells (Supplementary Data 1). We therefore examined the role of this protein in metastasis. An ES cell-like gene expression signature has been associated with an aggressive phenotype in cancer ${ }^{32}$, and so we examined the relation between ESRP1 expression and prognosis with the use of gene expression profiles of breast cancer patients ${ }^{33}$. A high level of ESRP1 expression was significantly associated with a lower rate of overall survival (Fig. 2b), suggesting that increased ESRP1 expression is related to the malignant behaviour of human breast cancer.

The abundance of ESRP1 mRNA was significantly higher in $\mathrm{CD} 44 \mathrm{v}^{+} 4 \mathrm{~T} 1$ cells than in $\mathrm{CD} 44 \mathrm{v}^{-} 4 \mathrm{~T} 1$ cells and $67 \mathrm{NR}$ cells (Fig. 2c), suggesting that ESRP1 regulates CD44v expression. We established $\mathrm{CD} 44 \mathrm{v}^{+} 4 \mathrm{~T} 1$ cells that stably express either a short hairpin RNA (shRNA) specific for ESRP1 mRNA (shESRP1 CD44v ${ }^{+}$ cells) or a corresponding scrambled (control) shRNA (shC CD44v ${ }^{+}$ cells) (Supplementary Methods). ESRP1 knockdown resulted in a switch in CD44 mRNA splicing that led to the generation of the CD44 standard isoform (CD44s) mRNA rather than CD44v mRNA (Fig. 2d). Furthermore, the mRNAs for Mena, fibroblast growth factor receptor 2 (FGFR2), and p120 catenin, whose splicing is also regulated by ESRP1 (ref. 14), underwent a shift in splicing pattern in shESRP1 CD $44 \mathrm{v}^{+}$cells (Fig. 2d). Flow cytometry also revealed that ESRP1 depletion resulted in a pronounced conversion from the production of CD44v to that of CD44s without an effect on the overall level of CD44 expression (Fig. 2e). To determine whether ESRP1 contributes to the metastatic behaviour of $\mathrm{CD} 44 \mathrm{v}^{+}$cells, we transplanted shC CD44v ${ }^{+}$or shESRP1 CD44v ${ }^{+}$cells orthotopically into mouse mammary glands. Although the incidence $\left(\mathrm{shC} \mathrm{CD} 44 \mathrm{v}^{+}\right.$, 
a

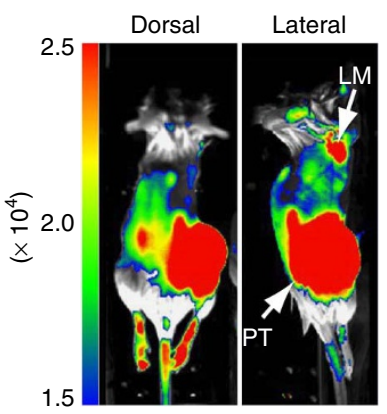

b

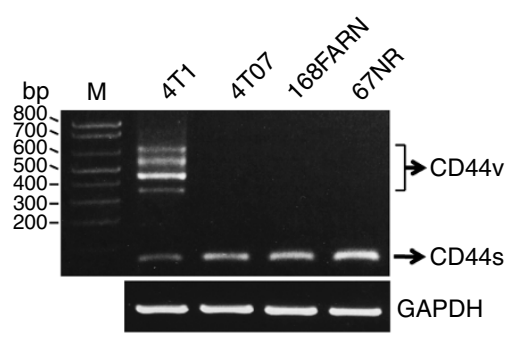

C

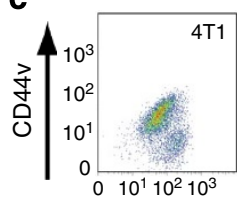

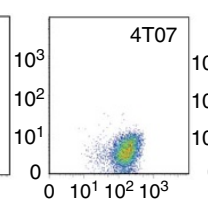
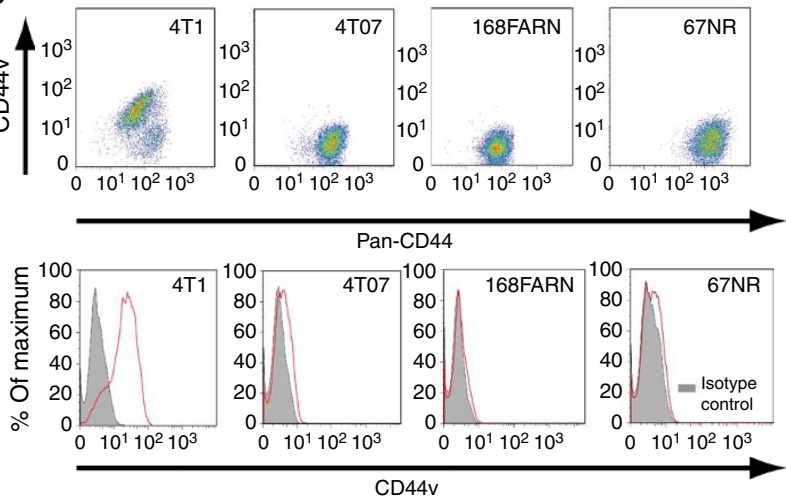

d
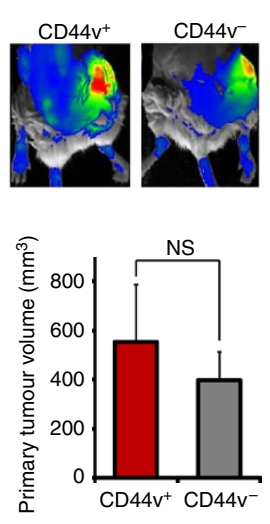

e
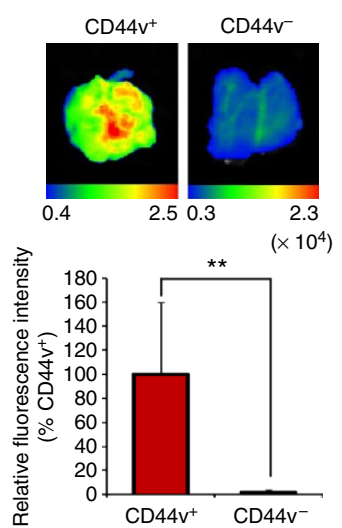

f

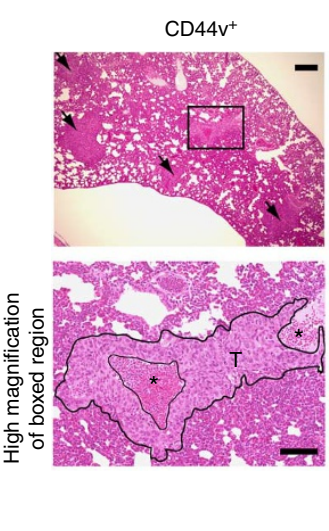

g

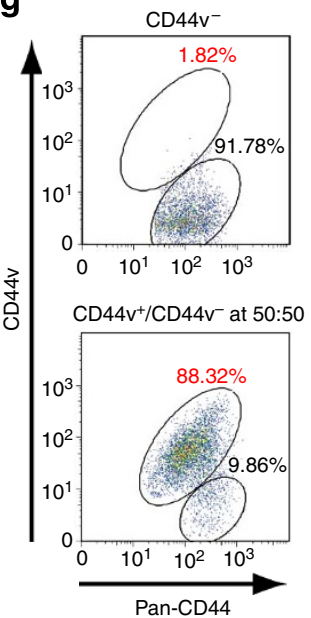

Figure 1 | Expression of CD44v in metastatic breast cancer cells with lung colonization potential. (a) IntegriSense fluorescence images of a representative mouse injected with $4 \mathrm{~T} 1$ cells $\left(1 \times 10^{5}\right)$ orthotopically into the mammary gland. Left colour bar and associated numbers indicate fluorescence intensity levels, with red and blue representing high and low fluorescence signals, respectively. LM, lung metastasis; PT, primary tumour. (b) RT-PCR analysis of total RNA from the indicated cell lines with primers targeted to exons 5 and 16 of the mouse CD44 gene as well as to the mouse glyceraldehyde3-phosphate dehydrogenase (Gapdh) gene (internal control). M, DNA size marker. (c) Flow cytometric analysis of CD44 isoform expression on the indicated cell lines with antibodies that recognize all isoforms of CD44 (pan-CD44) or only CD44v. Similar results were obtained in three independent experiments. (d) IntegriSense images of primary tumours formed as a result of orthotopic injection of sorted CD44v $\mathrm{v}^{+}$or $\mathrm{CD} 44 \mathrm{v}^{-} 4 \mathrm{~T} 1 \mathrm{cells}\left(1 \times 10^{5}\right)$ into the mammary gland of mice (upper). Tumour volume at 30 days after cell injection was calculated as length $\times\left(\right.$ width) ${ }^{2} / 2$ (bottom), and data are means \pm s.d. for eight animals per group. NS, not significant. (e) IntegriSense images of lung metastases formed in mice injected as in (d), and quantitative analysis of the total fluorescence intensity per lung metastatic lesion. Quantitative data are means \pm s.d. for 5 animals injected with CD44v ${ }^{+}$cells or $\mathrm{CD} 44 \mathrm{v}^{-}$cells. ${ }^{\star \star} P<0.01$ (Student's $t$-test). (f) Haematoxylin-eosin staining of lung metastases formed 30 days after orthotopic injection of CD44 $\mathrm{v}^{+}$ or $\mathrm{CD} 44 \mathrm{v}^{-}$cells into the mammary gland of recipient mice. The boxed regions in the upper panels are shown at higher magnification in the lower panels. Arrows indicate metastatic nodules in the lung; asterisks indicate blood vessels; T, tumour. Scale bars, $300 \mu \mathrm{m}$ (upper) or $100 \mu \mathrm{m}$ (lower). (g) Flow cytometric analysis of CD44 isoform expression on tumour cells (6-TG-resistant and lineage marker-negative (Lin ${ }^{-}$) cells) isolated from lung metastases at 30 days after intravenous injection of $\mathrm{CD} 44 \mathrm{v}^{-} 4 \mathrm{~T} 1$ cells $\left(1 \times 10^{4}\right)$ or both $\mathrm{CD} 44 \mathrm{v}^{+}$and $\mathrm{CD} 44 \mathrm{v}^{-} 4 \mathrm{~T} 1$ cells $\left(5 \times 10^{3}\right.$ cells each).

15/15; shESRP1 CD44v $\left.{ }^{+}, 15 / 15\right)$ and volume (Fig. 2f) of primary tumours formed by these cells were similar, the incidence of lung

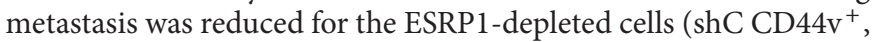
14/15; shESRP1 CD44v $\left.{ }^{+}, 6 / 15\right)$. Furthermore, the extent of lung metastases was reduced for shESRP1 CD44v ${ }^{+}$cells compared with shC CD44v ${ }^{+}$cells (Fig. $2 \mathrm{~g}$ ), suggesting that ESRP1 promotes lung colonization by $\mathrm{CD} 44 \mathrm{v}^{+} 4 \mathrm{~T} 1$ cells.

$\mathrm{CD}_{44 \mathrm{v}^{+}}$stem-like cells dominantly colonize and expand in the lung. We next examined whether metastasis-associated stress results in enrichment of ROS-resistant cells. We isolated tumour cells from the primary lesion (4T1PT) and lung metastases (4T1LM) formed by $4 \mathrm{~T} 1$ cells (Fig. 3a) and evaluated their intracellular ROS levels by staining with the fluorescent probe $2^{\prime}, 7^{\prime}$-dichlorofluorescein diacetate (DCFH-DA). ROS levels of 4T1LM cells were lower than those of 4T1PT cells in the absence or presence of hydrogen peroxide
$\left(\mathrm{H}_{2} \mathrm{O}_{2}\right)$ (Fig. 3b; Supplementary Fig. S2), indicating that 4T1LM cells have a higher ROS-defence capacity than 4T1PT cells. Furthermore, flow cytometry of cells labelled with 5-chloromethylfluorescein diacetate (CFMDA), a fluorescent probe for GSH (Supplementary Methods), revealed that intracellular GSH abundance in 4T1LM cells was greater than that of $4 \mathrm{~T} 1$ or $4 \mathrm{~T} 1 \mathrm{PT}$ cells (Fig. 3c). A luminescencebased assay that relies on the conversion of a luciferin derivative to luciferin in the presence of $\mathrm{GSH}^{18}$ also showed that the intracellular GSH content of 4T1LM cells was significantly greater than that of 4T1PT cells (Supplementary Fig. S2). Together, these results indicated that lung metastasis results in enrichment of ROS-resistant cells with high GSH levels. To examine whether CD44v-expressing cells maintain high GSH levels in vivo, we applied imaging mass spectrometry to visualize GSH and oxidized glutathione (GSSG) in frozen tissue samples ${ }^{34,35}$. CD44v ${ }^{+}$lung metastases formed by 4T1 cells manifested high levels of GSH but not of GSSG (Fig. 3d), 
a

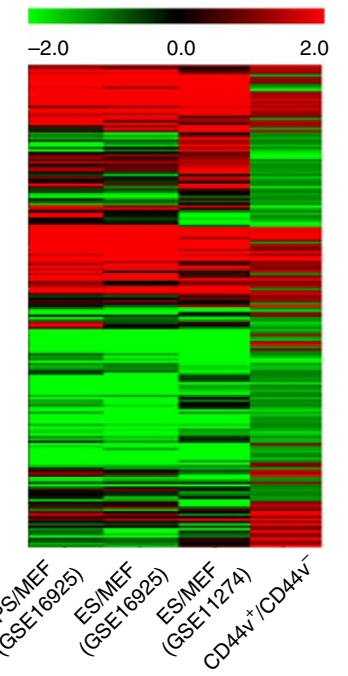

e

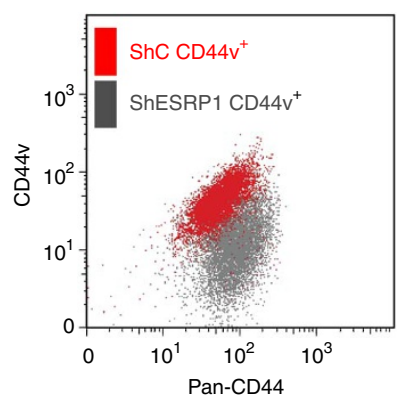

b

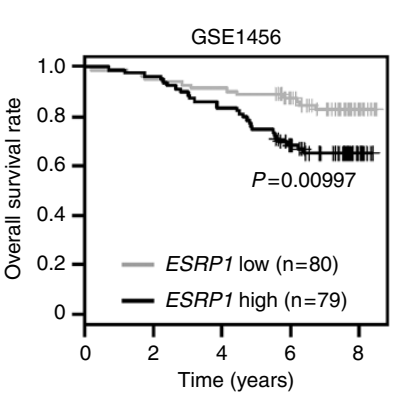

C

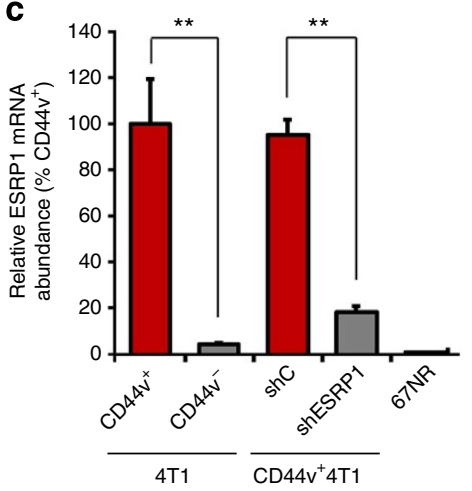

d

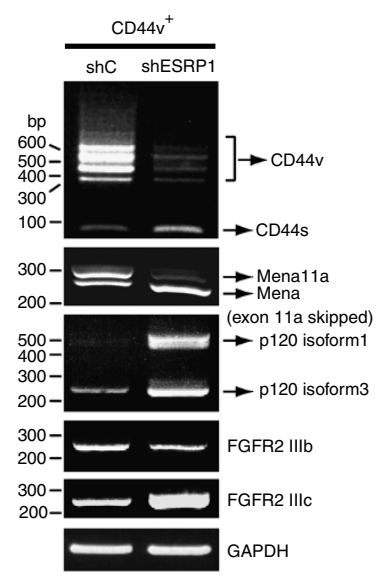

f

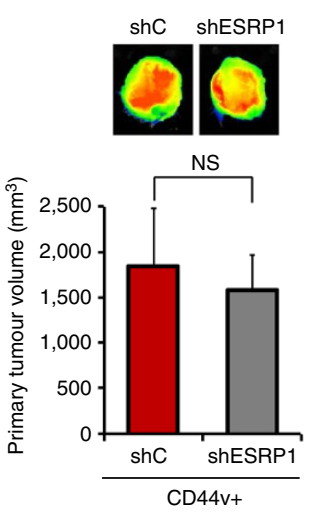

g
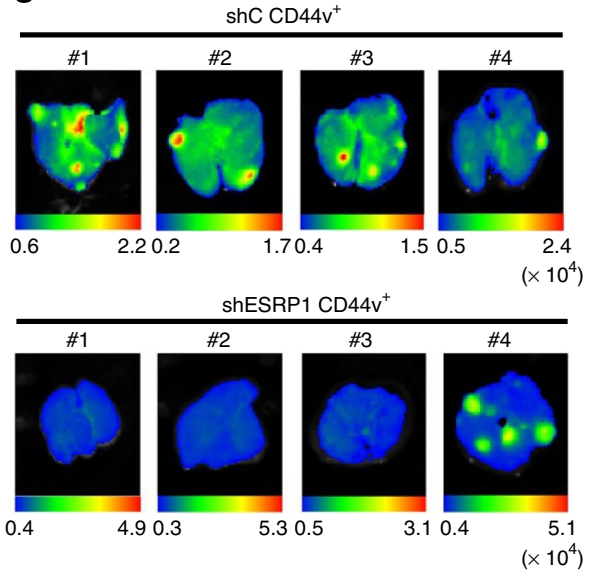

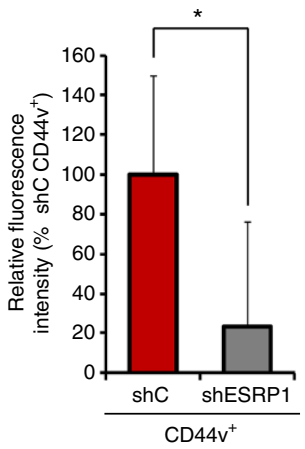

Figure 2 | Regulation of alternative splicing of CD44 mRNA and promotion of lung metastasis by ESRP1. (a) GSEA of microarray data for CD44v ${ }^{+}$ cell/CD44v- cell, ES cell/MEF (GSE16925 and GSE11274), and iPS cell/MEF (GSE16925) profiles. (b) Kaplan-Meier plots of overall survival according to ESRP1 (219121_S_at) expression level for a breast cancer patient set (GSE1456, $n=159$ ). (c) Quantitative RT-PCR analysis of the abundance of ESRP1 mRNA

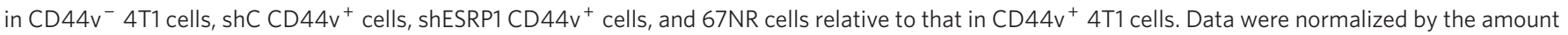
of Gapdh mRNA and are means \pm s.d. from three independent experiments. ${ }^{\star \star} P<0.01$ (Student's $t$-test). (d) RT-PCR analysis of splice variant mRNAs for CD44, Mena, p120 catenin, and FGFR2 in shC CD44v ${ }^{+}$and shESRP1 CD44v ${ }^{+}$cells. (e) Flow cytometric analysis of CD44 expression on shC CD44v ${ }^{+}$and shESRP1 CD44 $v^{+}$cells with antibodies to pan-CD44 and to CD44v. (f) IntegriSense images of primary tumours formed in mice by orthotopically injected shC CD $44 v^{+}$or shESRP1 CD $44 v^{+}$cells $\left(1 \times 10^{5}\right)$ as well as tumour volume at 30 days after cell injection. Quantitative data are means \pm s.d. for five animals per group. (g) IntegriSense images of lung metastases and quantitative analysis of the total fluorescence signal intensity per lung metastatic lesion for mice injected as in (f). Quantitative data are means \pm s.d. for four animals per group. ${ }^{\star} P<0.05$ (Student's $t$-test).

suggesting that CD44v confers ROS resistance to cancer cells through the promotion of GSH synthesis. We then examined the role of GSH in lung colonization by $\mathrm{CD}_{4} 4 \mathrm{v}^{+}$cells with the use of L-buthionine sulphoximine (BSO), which inhibits $\gamma$-glutamylcysteine synthase ${ }^{36}$ and thereby depletes intracellular GSH (Supplementary Fig. S2). Lung colonization by L-buthionine sulphoximine-treated CD44v ${ }^{+}$ cells was significantly inhibited compared with that of control cells (Supplementary Fig. S2), suggesting that a high intracellular GSH level enhances the lung colonization potential of CD $44 \mathrm{v}^{+}$cells.

Breast cancer stem cells manifest an increased ROS defence capacity relative to their nontumorigenic progeny ${ }^{37}$. We therefore examined 4T1LM cells for the presence of stem-like cells with the use of ALDEFLUOR, a fluorescent probe for aldehyde dehydrogenase $(\mathrm{ALDH})$ activity, a marker for stem-like cancer cells ${ }^{38}$. 4T1LM cells contained a much larger proportion of ALDEFLUOR-positive cells compared with $4 \mathrm{~T} 1$ or $4 \mathrm{~T} 1 \mathrm{PT}$ cells (Fig. 3e). Furthermore, most ALDEFLUOR-positive 4T1LM cells expressed CD44v
(Fig. 3f), suggesting that $\mathrm{CD} 44 \mathrm{v}^{+}$stem-like cells may expand during lung colonization. In contrast, the proportions of ALDEFLUOR-positive cells among noninjected CD44v ${ }^{+}$or CD44v ${ }^{-} 4 \mathrm{~T} 1$ cells were similar (Fig. 3g). These results suggested that the difference in metastatic behaviour between $\mathrm{CD} 44 \mathrm{v}^{+}$and $\mathrm{CD} 44 \mathrm{v}^{-}$cells is determined by the difference in ROS resistance rather than by a difference in the size of the pre-existing stem-like cell population.

CD44 splicing enhances ROS defence in metastatic 4T1 cells. We examined the role of $\mathrm{xCT}$ in lung metastasis and found that the level of $\mathrm{xCT}$ expression on the surface of $4 \mathrm{~T} 1$ cells was greater than that on 67NR (nonmetastatic) cells (Fig. 4a). It was also higher on $\mathrm{CD} 44 \mathrm{v}^{+}$cells compared with $\mathrm{CD} 44 \mathrm{v}^{-}$cells. xCT was downregulated on $\mathrm{CD}_{4} 4 \mathrm{v}^{+}$cells by RNA interference-mediated depletion of ESRP1 (Fig. 4b), suggesting that ESRP1-dependent splicing of CD44 mRNA controls the cell surface expression of xCT. Consistent with these results (Fig. 4a,b), the intracellular GSH content was 
a

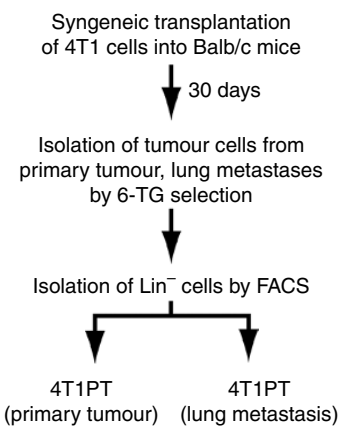

b
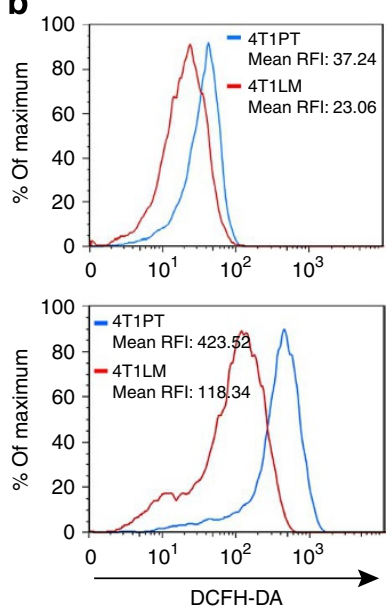

C

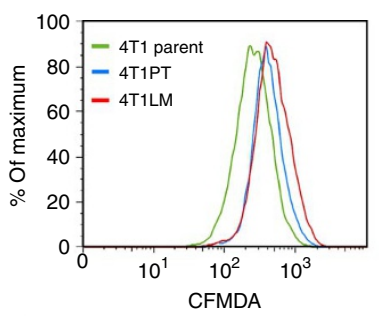

4T1 parent: Mean RFI: $313.166 \pm 16.56$ 4T1PT: Mean RFI: $423.54 \pm 27.05]$ ** 4T1LM: Mean RFI:495.51 \pm 15.60$]$ ** d
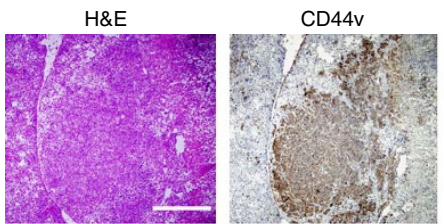

GSH
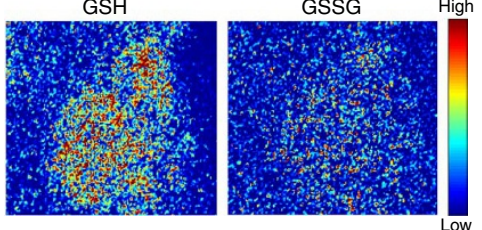

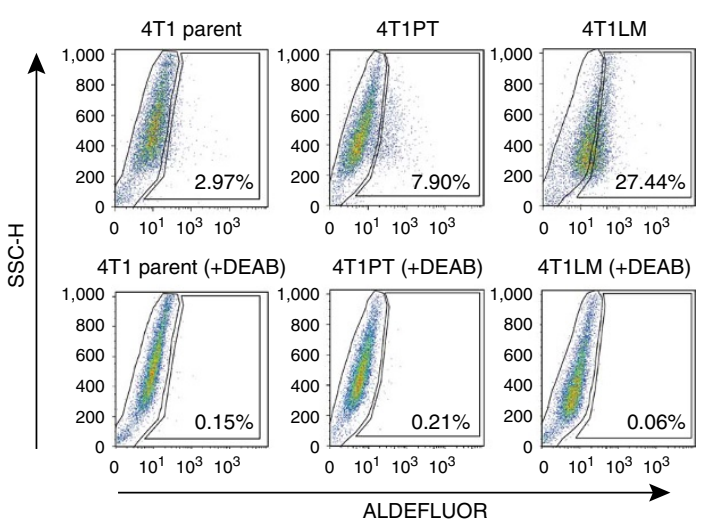

f

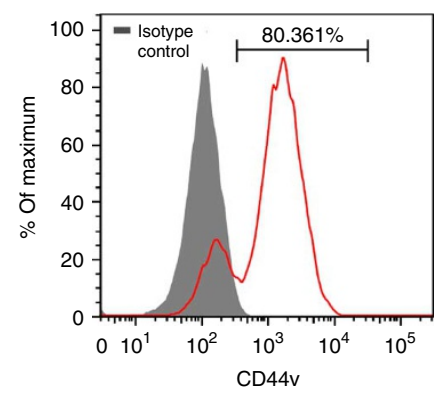

g

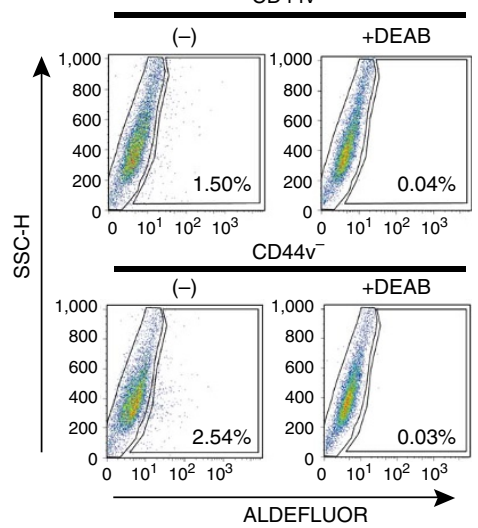

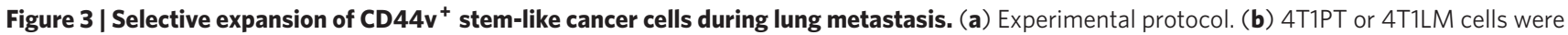
incubated with or without $500 \mu \mathrm{M} \mathrm{H}_{2} \mathrm{O}_{2}$ for 20 min, stained with DCFH-DA, and subjected to flow cytometric analysis. RFI, relative fluorescence intensity. Similar results were obtained in three independent experiments. (c) Flow cytometric analysis of parental 4T1 as well as 4T1PT and 4T1LM cells stained with CFMDA (upper). Mean \pm s.d. values for RFI from five independent experiments are also shown (lower); ${ }^{* \star} P<0.01$ (Student's $t$-test). (d) Haematoxylineosin (H\&E) staining and immunohistochemical staining of CD44v (upper panels) as well as imaging mass spectrometry of GSH and GSSG (lower panels) in lung metastases formed by $4 \mathrm{~T} 1$ cells. The colour bar indicates peak intensity levels at $\mathrm{m} / \mathrm{z} 306.0$ (GSH) or 611.1 (GSSG), with red and blue representing high and low signals, respectively. Scale bar, $500 \mu \mathrm{m}$. (e) Flow cytometry of 4T1, 4T1PT, or 4T1LM cells incubated with the ALDEFLUOR substrate (BAAA) with or without the specific inhibitor (DEAB) to establish the baseline fluorescence and to define the ALDEFLUOR-positive region. SSC-H, side scatter. (f) Flow cytometric analysis of CD44v expression in ALDEFLUOR-positive 4T1LM cells. Cells were stained with antibodies to CD44v after incubation with BAAA in the absence or presence of DEAB. Similar results were obtained in three independent experiments. (g) Flow cytometric analysis of CD44 ${ }^{+}$or CD44v $v^{-} 4 T 1$ cells subjected to the ALDEFLUOR assay as in (e). Similar results were obtained in three independent experiments.

significantly higher for $4 \mathrm{~T} 1$ cells than for $67 \mathrm{NR}$ cells, for $\mathrm{CD} 44 \mathrm{v}^{+}$cells compared with CD44v $\mathrm{v}^{-}$cells, and in shC CD44v ${ }^{+}$cells compared with shESRP1 CD $44 \mathrm{v}^{+}$cells (Fig. 4c). These findings suggested that ESRP1-regulated CD44v expression increases the amount of xCT at the cell surface and thereby contributes to the maintenance of high GSH levels. To investigate whether xCT activity promotes lung colonization by CD44v-expressing cells, we examined the effect of the specific $\mathrm{xCT}$ inhibitor sulfasalazine (Supplementary Methods) ${ }^{18,39}$. Two weeks after intravenous injection of $\mathrm{CD}_{44 \mathrm{v}}{ }^{+}$cells, lung metastasis was suppressed in sulfasalazine-treated mice compared with saline-treated controls (Fig. 4d), suggesting that xCT has a functional role in lung colonization.

ESRP1 affects the splicing of mRNAs for various proteins including FGFR2, p120 catenin, and Mena as well as CD44 (ref. 14). To examine the contribution of CD44v to ESRP1-dependent lung metastasis, we introduced CD44v8-10 complementary DNA ${ }^{18}$ into shESRP1 CD $44 v^{+}$cells to generate cells that stably express CD44v810 as well as ESRP1 shRNA (Fig. 4e; Supplementary Fig. S3). Cells expressing CD44v8-10 showed a significantly higher level of GSH compared with cells transfected with the empty vector (Fig. 4f). Furthermore, the increase in ROS level after exposure to $\mathrm{H}_{2} \mathrm{O}_{2}$ was reduced by forced expression of CD44v8-10 (Fig. 4g), indicating that CD44v8-10 expression enhanced ROS defence in ESRP1-depleted cells. ROS abundance in the absence of $\mathrm{H}_{2} \mathrm{O}_{2}$ was not affected by CD44v8-10 expression (Supplementary Fig. S3), suggesting that CD44v8-10 protects cancer cells on exposure to excessive amounts of ROS.

Finally, forced expression of CD44v8-10 resulted in a marked increase in the lung metastatic potential of ESRP1-depleted cells (Fig. 4h). Together, these data suggested that alternative splicing of CD44 mRNA regulated by ESRP1 enhances xCT-dependent ROS defence in cancer cells and thereby promotes efficient lung colonization.

Epigenetic regulation of ESRP1 expression in 4T1 cells. ESRP1 expression was recently shown to be downregulated in cells 
a

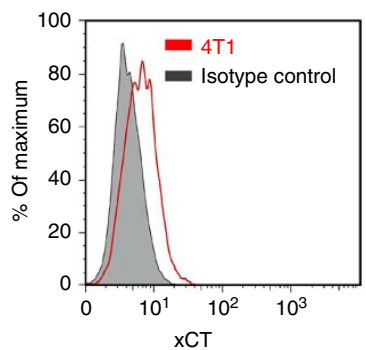

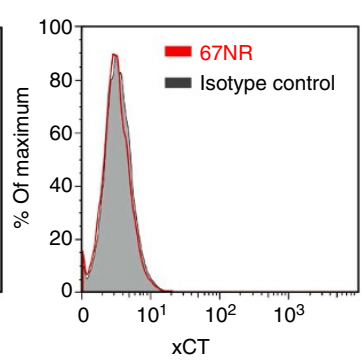

b

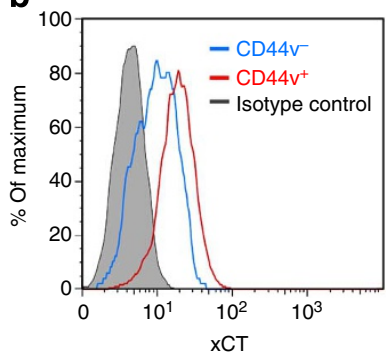

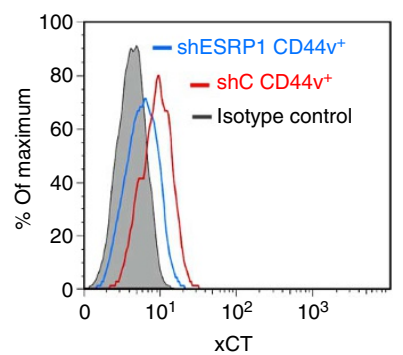

C

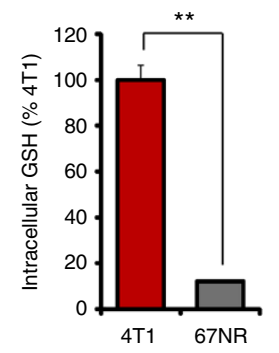

d

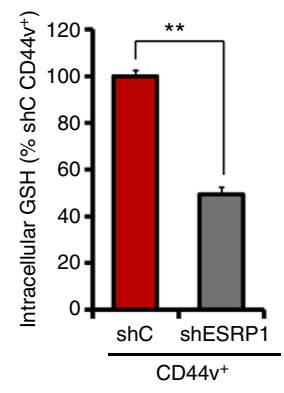

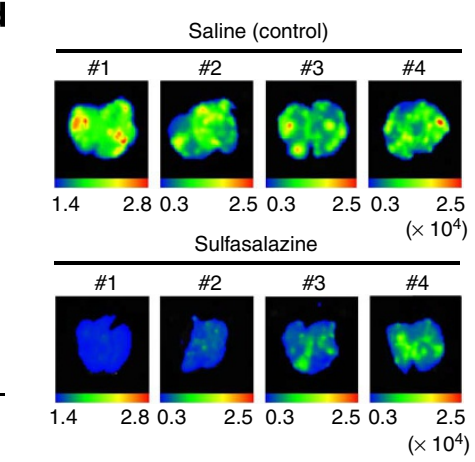

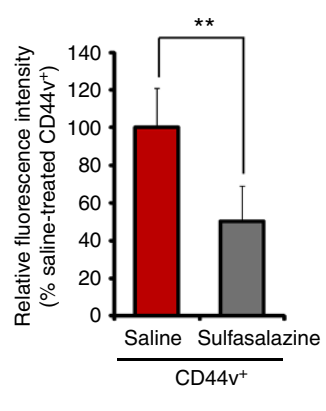

e

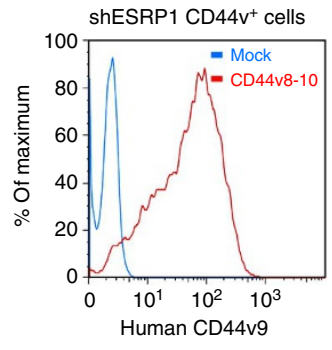

f

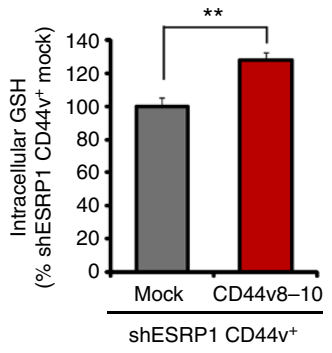

g

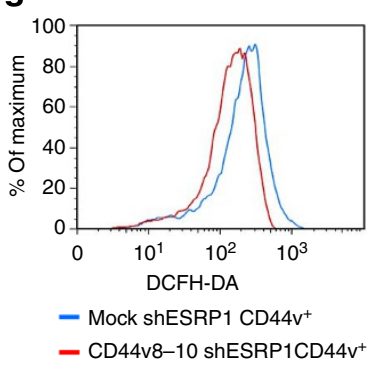

h

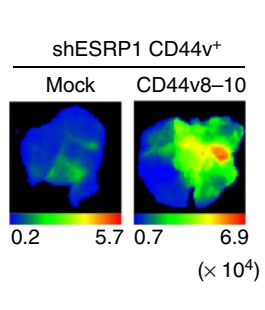

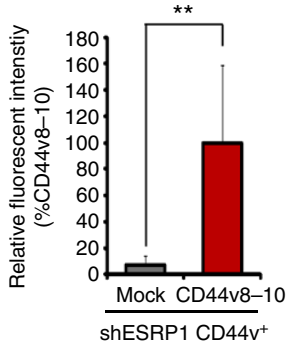

Figure 4 | CD44 splicing enhances ROS defence and lung colonization potential. (a) Flow cytometric analysis of xCT expression on 4T1 or 67NR cells.

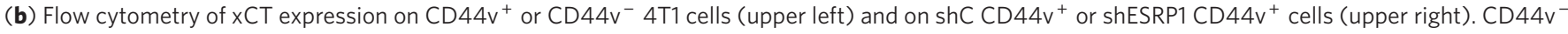

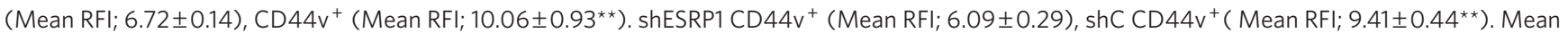
\pm s.d. values for RFI from five independent experiments. ${ }^{\star \star} P<0.01$ (Student's $t$-test). (c) Intracellular GSH content of $4 T 1$ or $67 N R$ cells (left), CD44 $v^{+}$ or $C D 44 v^{-} 4 T 1$ cells (middle), and shC CD44 $v^{+}$or shESRP1 CD $44 v^{+}$cells (right). Data are means \pm s.d. from five independent experiments. ${ }^{\star \star} P<0.01$ (Student's t-test). (d) IntegriSense images of lung metastases formed in mice 2 weeks after intravenous injection of CD $44 \mathrm{v}^{+}$cells $\left(1 \times 10^{5}\right)$ and the onset of treatment with sulfasalazine or saline. The fluorescence signal intensity of each lung metastasis was also measured; data are means \pm s.d. for four animals treated with saline and six animals treated with sulfasalazine. ${ }^{\star \star} P<0.01$ (Student's $t$-test). (e) Flow cytometric analysis of human CD44v9 expression on the surface of shESRP1 CD44v ${ }^{+}$cells stably expressing human CD44v8-10 or stably transfected with the empty vector (mock).

(f) Intracellular GSH content of cells transfected as in (e). Data are means $\pm s$.d. from five independent experiments. ${ }^{\star \star} P<0.01$ (Student's $t$-test).

(g) Mock-transfected or CD44v8-10-expressing shESRP1 CD44v ${ }^{+}$cells were incubated with $500 \mu \mathrm{M} \mathrm{H}_{2} \mathrm{O}_{2}$ for 20 min, stained with DCFH-DA, and subjected to flow cytometric analysis. Mock-transfected shESRP1 CD44v ${ }^{+}$(Mean RFl; 232.73 44.89), CD44v8-10-expressing shC CD44v ${ }^{+}$(Mean RFl; $\left.160.19 \pm 8.82^{\star \star}\right)$. Mean \pm s.d. values of RFI from five independent experiments. ${ }^{\star \star} P<0.01$ (Student's $t$-test). (h) IntegriSense images of lung metastases formed 30 days after orthotopic injection of cells $\left(1 \times 10^{5}\right)$ transfected as in $(\mathbf{e})$ into the mammary gland of recipient mice. The fluorescence signal intensity of each lung metastasis was also measured; data are means \pm s.d. for five animals per group. ${ }^{\star \star} P<0.01$ (Student's $t$-test).

undergoing the epithelial-mesenchymal transition (EMT) ${ }^{40}$. To investigate the relevance of EMT status to ESRP1 expression in $\mathrm{CD} 44 \mathrm{v}^{+}$and $\mathrm{CD} 44 \mathrm{v}^{-} 4 \mathrm{~T} 1$ cells, we examined the expression of EMT markers and Twist, an EMT-inducing transcription factor that is highly expressed in $4 \mathrm{~T} 1$ cells $^{41}$. Immunoblot analysis showed that both $\mathrm{CD} 44 \mathrm{v}^{+}$and $\mathrm{CD} 44 \mathrm{v}^{-}$cells express the epithelial markers E-cadherin and ZO-1 and that the expression level of Twist was similar in the two cell subpopulations (Fig. 5a), suggesting that ESRP1 expression in $\mathrm{CD} 44 \mathrm{v}^{+}$and $\mathrm{CD} 44 \mathrm{v}^{-} 4 \mathrm{~T} 1$ cells is regulated independently of EMT-related mechanisms.

Posttranscriptional modifications of histones that affect chromatin structure influence ESRP1-mediated alternative splicing ${ }^{42,43}$, suggesting that alternative splicing is tightly regulated at the chromatin level. We therefore examined whether ESRP1 expression might also be regulated epigenetically through histone modification by performing chromatin immunoprecipitation (ChIP) sequencing analysis of the ESRP1 locus in CD44v $\mathrm{v}^{+}$and $\mathrm{CD} 44 \mathrm{v}^{-}$ cells. CD $44 v^{+}$cells manifested a marked increase in the amount of trimethylated lysine- 4 of histone $\mathrm{H} 3$ (H3K4me3), which marks open chromatin and active transcription ${ }^{44}$, compared with $\mathrm{CD}_{44 \mathrm{v}^{-}}$cells (Fig. 5b). Conversely, the amount of trimethylated lysine-27 of histone $\mathrm{H} 3$ (H3K27me3), which is associated with gene silencing ${ }^{45}$, was increased in CD44v ${ }^{-}$cells (Fig. 5b). Consistent with these histone profiles, RNA polymerase II was enriched at the ESRP1 locus 
a

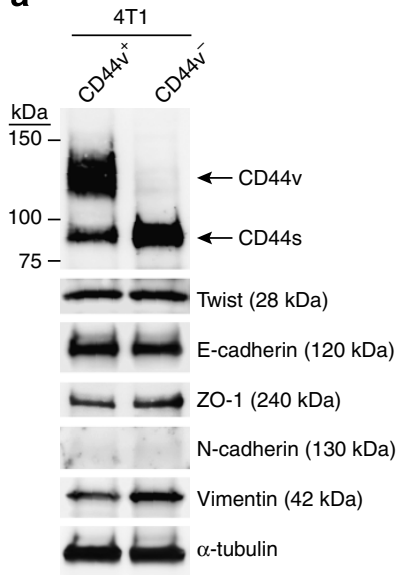

b

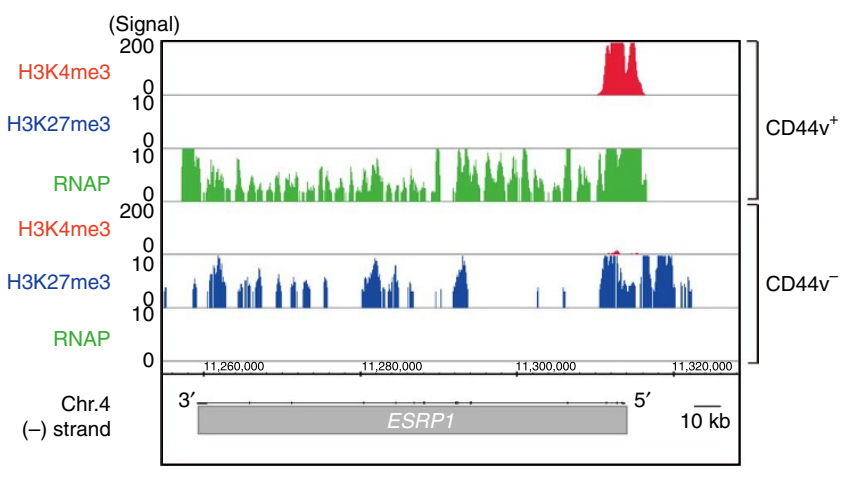

Figure 5 | EMT marker expression and epigenetic status of the ESRP1 locus in CD44v ${ }^{+}$or CD44v- $\mathbf{4 T 1}$ cells. (a) Immunoblot analysis of the epithelial markers (E-cadherin and ZO-1) and the mesenchymal markers ( $N$-cadherin and Vimentin) and Twist expression in CD44v ${ }^{+}$or CD44v ${ }^{-} 4 T 1$ cells. $\alpha$-Tubulin was analysed as a loading control. (b) Enrichment of histone H3K4me3 and H3K27me3 as well as of RNA polymerase II (RNAP) at the ESRP1 locus on mouse chromosome 4 in $\mathrm{CD}_{4} 4^{+}$or $\mathrm{CD} 44^{-} 4 \mathrm{~T} 1$ cells as visualized with the $390-\mathrm{kbp}$ UCSC mm9 genome browser. The gene is transcribed from right to left.

in $\mathrm{CD} 44 \mathrm{v}^{+}$cells compared with $\mathrm{CD} 44 \mathrm{v}^{-}$cells (Fig. 5b). Together, these findings suggested that ESRP1 expression in metastatic cancer cells is controlled at the chromatin level.

\section{Discussion}

Alternative splicing generates multiple mRNAs from a single-gene transcript, thereby greatly expanding proteomic diversity. Although only a small number of cell type-specific splicing regulators have been identified in mammals, numerous additional regulators will likely be found among the large number of uncharacterized RNAbinding proteins. ESRPs regulate the splicing of transcripts for epithelial- or mesenchymal-specific isoforms of proteins including CD44, FGFR2, p120 catenin, and Mena ${ }^{14}$. The expression of CD44v but not CD44s has been shown to promote the aggressive behaviour in several types of cancer cells including pancreatic cancer ${ }^{10,46}$ and lymphoma ${ }^{47}$. We have now shown that depletion of ESRP1 in metastatic breast cancer cells changed the phenotype of these cells from $\mathrm{CD} 44 \mathrm{v}^{+}$to $\mathrm{CD} 44 \mathrm{~s}^{+}$, without affecting the overall level of CD44 expression on the cell surface, and resulted in the suppression of lung metastasis. Consistent with these results, a high expression level of ESRP1 in tumour specimens was associated with a poor prognosis in breast cancer patients.

Metastasis allows cancer cells to avoid oxidative damage caused by excess ROS in the primary tumour ${ }^{48}$, with metastatic cancer cells often being required to adapt to the selective pressure of the tumour microenvironment ${ }^{19}$. Neutrophils were recently shown to accumulate in the lung before the arrival of metastatic cells as well as to inhibit lung metastasis of $4 \mathrm{~T} 1$ cells through NADPH-dependent $\mathrm{H}_{2} \mathrm{O}_{2}$ generation ${ }^{21}$. Neutralization of such oxidative stress at potential sites of metastasis may thus be required for cancer cells to establish metastatic lesions.

The cystine transporter $\mathrm{xCT}$ promotes GSH synthesis and ROS defence in cancer cells and thereby has a key role in resistance to cancer therapy ${ }^{18,27}$, and it has recently been implicated in cancer metastasis ${ }^{49}$. We found that ESRP1-dependent alternative splicing of CD44 mRNA increases both the intracellular GSH level and lung metastatic potential in breast cancer cells. Furthermore, forced expression of CD44v8-10 in ESRP1-depleted cells restored GSH content and lung metastatic ability to levels observed in ESRP1replete cells. ESRP1-regulated alternative splicing of CD44 mRNA thus enhances xCT-dependent ROS defence and thereby allows cancer cells to evade metastatic stress.
ALDH activity, in addition to CD44 expression, has been shown to be a marker for stem-like cells in breast cancer ${ }^{38}$. $\mathrm{ALDH}^{\text {high }} \mathrm{CD} 44^{+}$cells among human breast cancer cell lines show increased tumour formation and lung colonization abilities compared with $\mathrm{ALDH}{ }^{\text {low }} \mathrm{CD} 44^{\text {low } /-}$ cells ${ }^{6}$. We found that both $\mathrm{CD} 44 \mathrm{v}^{+}$ and $\mathrm{CD} 44 \mathrm{v}^{-} 4 \mathrm{~T} 1$ cell subpopulations contain a small number of ALDEFLUOR-positive stem-like cells but that these stem-like cells among the $\mathrm{CD} 44 \mathrm{v}^{+}$subpopulation underwent selective expansion in lung metastases. CD44v may therefore not be a specific marker for stem-like cancer cells but rather may be required to protect stem-like cells against oxidative stress.

Induction of the EMT results in downregulation of ESRP1 expression $^{40}$ and thereby triggers a CD44 isoform switch from CD44v to $\mathrm{CD} 44 \mathrm{~s}$ in mammary epithelial cells 14,50 . Given that $\mathrm{CD} 44 \mathrm{v}^{+}$ and $\mathrm{CD} 44 \mathrm{v}^{-} 4 \mathrm{~T} 1$ cells manifest similar expression levels of both epithelial and mesenchymal markers, the expression of ESRP1 as well as that of CD44v in these cells do not seem to be dependent on EMT status. ChIP sequencing analysis at the ESRP1 locus revealed that $\mathrm{CD} 44 \mathrm{v}^{+}$cells manifest H3K4me3 (a mark of active transcription) at the transcription start site, whereas $\mathrm{CD} 44 \mathrm{v}^{-}$cells manifest H3K27me3 (a mark of transcriptional repression). ESRP1 expression may thus be affected by the epigenetic status of the ESRP1 locus as well as by the EMT.

Chromatin modifications including DNA and histone methylation at metastasis-related genes have been considered potential targets for the treatment of cancer metastasis ${ }^{51}$. Therapies targeted to the epigenetic regulation of ESRP1 as well as those that target CD44v-mediated stabilization of xCT might be expected to perturb the ROS resistance of metastatic stem-like cancer cells and thereby to render them susceptible to currently available cancer treatments.

\section{Methods}

Cell culture. The murine breast cancer cell line 4T1 (American Type Culture Collection, Rockville, MD) as well as $\mathrm{CD} 44 \mathrm{v}^{+}$and $\mathrm{CD} 44 \mathrm{v}^{-}$cells sorted therefrom were cultured under $5 \% \mathrm{CO}_{2}$ at $37^{\circ} \mathrm{C}$ in RPMI 1640 medium (Sigma, St. Louis, MO) supplemented with $10 \%$ fetal bovine serum. 67NR, 168FARN, and $4 \mathrm{~T} 07$ cells (kindly provided by Link Genomics, Tokyo, Japan) were cultured under $5 \% \mathrm{CO}_{2}$ at $37^{\circ} \mathrm{C}$ in Dulbecco's modified Eagle's medium-F12 (Sigma) supplemented with $10 \%$ fetal bovine serum.

Mice. Wild-type Balb/c mice were obtained from CLEA Japan or Japan SLC (Tokyo, Japan). They were bred and maintained in the animal facility at Keio University according to institutional guidelines. All animal experiments were performed in accordance with protocols approved by the Ethics Committee of Keio University. 
Orthotopic transplantation and metastasis assay. Parental, $\mathrm{CD} 44 \mathrm{v}^{+}$, or $\mathrm{CD} 44 \mathrm{v}^{-} 4 \mathrm{~T} 1$ cells $\left(1 \times 10^{5}\right)$ were orthotopically injected into the fourth mammary gland of syngeneic 8-to-10-week-old female wild-type Balb/c mice. At 30 days after transplantation, the mice were killed and the lungs removed. Quantification of lung metastasis was performed by imaging as described below.

IntegriSense imaging. Twenty-four hours before imaging, mice were injected intravenously with $2 \mathrm{nmol}$ of IntegriSense 750 (VisEn Medical, Bedford, MA). Fluorescence imaging was performed with a ClairvivoOPT in vivo fluorescence imager (Shimadzu), with excitation at $785 \mathrm{~nm}$ with a laser diode and detection of fluorescence with an 845/55-nm band-pass filter. For quantitative comparisons, the total fluorescence signal intensity (pixel count) in a region of interest corresponding to each lung metastasis was measured.

Tumour cell isolation and flow cytometry. 4T1PT or 4T1LM cells were isolated from primary tumours or lung metastases, respectively, formed 30 days after orthotopic injection of $4 \mathrm{~T} 1$ cells $\left(1 \times 10^{5}\right)$ into the mammary gland of recipient mice. Primary tumours or lung metastases were digested for 4 to $5 \mathrm{~h}$ at $37^{\circ} \mathrm{C}$ in Ham's F12 medium supplemented with 5\% fetal bovine serum, penicillin $\left(100 \mathrm{U} \mathrm{ml}^{-1}\right)$, streptomycin $\left(100 \mu \mathrm{g} \mathrm{ml}^{-1}\right)$, bovine insulin $\left(5 \mu \mathrm{g} \mathrm{ml}^{-1}\right)$, collagenase $\left(300 \mathrm{U} \mathrm{ml}^{-1}\right)$, and hyaluronidase $\left(100 \mathrm{U} \mathrm{ml}^{-1}\right)$. Red blood cells were then lysed by the addition of $\mathrm{NH}_{4} \mathrm{Cl}$ to a final concentration of $100 \mathrm{mM}$ at room temperature, and tissue fragments were dissociated by gentle pipetting first in the presence of $0.25 \%$ trypsin for 1 to $2 \mathrm{~min}$ and then in the additional presence of dispase $\left(5 \mathrm{mg} \mathrm{ml}^{-1}\right)$ and DNase I $\left(0.1 \mathrm{mg} \mathrm{ml}^{-1}\right)$ for $2 \mathrm{~min}$. All reagents were obtained from Stemcell Technologies (Vancouver, Canada). The mixture was then filtered through a 40- $\mu \mathrm{m}$ nylon mesh to yield a single-cell suspension, and the cells were cultured in the presence of $0.4 \mu \mathrm{M}$ 6-TG (Sigma) for 2 to 3 days and then subjected to FACS to isolate $\mathrm{Lin}^{-}$cells. Cultured cells were dissociated by exposure to enzyme-free, Hanks-based Cell Dissociation Buffer (GIBCO-Invitrogen, Tokyo, Japan). For flow cytometric analysis or FACS, single-cell suspensions were incubated with antibodies for $20 \mathrm{~min}$ at $4^{\circ} \mathrm{C}$. Antibodies included phycoerythrin- and Cy7-conjugated antibodies to the lineage markers (Lin) CD31, CD45, and TER119 (BioLegend, San Diego, CA, USA), phycoerythrin-conjugated antibodies to pan-CD44 (IM7; eBioscience, San Diego, CA, USA), antibodies to xCT (Abcam, Cambridge, UK), allophycocyanin-conjugated antibodies specific for mouse $\mathrm{CD} 44 \mathrm{v}^{52}$ and fluorescein isothiocyanate-conjugated antibodies to human CD44v9 (ref. 18). Apoptotic cells were excluded for all flow cytometric analysis and FACS by elimination of cells positive for staining with propidium iodide. Flow cytometric analysis and FACS were performed with a FACSCalibur instrument (BD Biosciences, Tokyo, Japan) and either a FACSAria Cell Sorter (BD Biosciences) or MoFlo Cell Sorter (Beckman Coulter, Tokyo, Japan), respectively. For measurement of ROS or GSH levels, cells were incubated with $10 \mu \mathrm{M}$ DCFH-DA or CFMDA (Invitrogen/Molecular Probes, Tokyo, Japan), respectively, for $15 \mathrm{~min}$ at $37^{\circ} \mathrm{C}$, washed twice with phosphatebuffered saline, and subjected to flow cytometric analysis.

Immunoblot analysis. Immunoblot analysis was performed, as described previously ${ }^{53}$, and with primary antibodies including those to pan-CD44 (IM7; BD Pharmingen, Tokyo, Japan; 500x dilution), E-cadherin (BD Pharmingen; 1,000 $\times$ dilution), ZO-1, (Invitrogen, Tokyo, Japan; 1000 $\times$ dilution), Twist (H-81; Santa Cruz Biotechnology, Santa Cruz, CA, USA; 200× dilution), N-cadherin (N19; Santa Cruz; 1,000× dilution), Vimentin (BD Pharmingen; 200× dilution), and $\alpha$-Tubulin (Sigma; $1,000 \times$ dilution).

ALDEFLUOR assay. An ALDEFLUOR kit (StemCell Technologies) was used to detect cells with a high ALDH activity. Cells were suspended in ALDEFLUOR assay buffer containing the ALDH substrate BODIPY aminoacetaldehyde (BAAA) and incubated for $40 \mathrm{~min}$ at $37^{\circ} \mathrm{C}$. As a negative control, cells were incubated in the additional presence of diethylaminobenzaldehyde (DEAB), a specific ALDH inhibitor.

Imaging mass spectrometry. $4 \mathrm{~T} 1$ lung metastasis tissues snap-frozen in liquid nitrogen were dissected to prepare cryosections with $5-\mu \mathrm{m}$ thickness by use of a cryostat (CM 1900; Leica Microsystems, Wetzlar, Germany). The sections were thaw-mounted on indium-tin oxide slides (Bruker Daltonik $\mathrm{GmbH}$, Bremen, Germany) and were dried in silica gel-containing plastic tubes and, then, sprayed with 9-aminoacridine (9-AA, $20 \mathrm{mg}$ in $4 \mathrm{ml} 70 \% \mathrm{MeOH}$ ) by use of a 0.2 -mm nozzle calibre airbrush (Procon boy FWA Platinum; Mr Hobby, Tokyo, Japan) to conduct matrix-assisted laser desorption/ionization (MALDI) imaging mass spectrometry in negative ion mode ${ }^{34,35}$. Adjacent sections were fixed with $4 \%$ buffered formalin (Nacalai Tesque, Kyoto, Japan) and stained with anti-CD44v antibody ${ }^{52}$. All the MALDI imaging experiments was carried out in negative-ion mode using a prototype Mass Microscope (Shimadzu Corporation, Kyoto, Japan). The laser power was adjusted to the desired intensities. MALDI mass spectra were acquired under the conditions laser diameter $10 \mu \mathrm{m}, 80$ shots per spot, scanning pitch $10 \mu \mathrm{m}$ and scanning mass range from $\mathrm{m} / \mathrm{z} 260$ to $\mathrm{m} / \mathrm{z} 670$. Regions of the tissue samples exposed to the laser irradiation were determined by light microscopic observation.

GSEA. To detect overlap in gene expression profiles among multiple sets of genes, we used GSEA with the Kolmogorov-Smirnov enrichment algorithm and 400 random permutations to determine statistical significance. We first generated $\mathrm{CD} 44 \mathrm{v}^{+} / \mathrm{CD} 44 \mathrm{v}^{-} \log _{2}$ ratio data from our microarray experiment and divided genes into those whose expression was upregulated $\left(\log _{2}\right.$ ratio $\left.>0\right)$ or downregulated $\left(\log _{2}\right.$ ratio $\left.<0\right)$. Second, we collected public microarray data (GSE11274 and GSE16925) from the GEO database and calculated the $P$-value ( $t$ test) and $\log _{2}$ ratio for ES cells/MEFs or iPS cells/MEFs with the use of the SAM R-package. We extracted the genes with a $>2.0$-fold change in expression (upregulated) or $<0.5$-fold change (downregulated) on average and a SAM $P$-value of $<0.05$. Third, up- or down-regulated gene sets in our CD $44 \mathrm{v}^{+} / \mathrm{CD} 44 \mathrm{v}^{-}$microarray experiment were compared with the ES and iPS cell signature gene sets by GSEA.

ChIP sequencing and data analysis. ChIP was performed as previously described ${ }^{54}$. CD $44 \mathrm{v}^{+}$or $\mathrm{CD} 44 \mathrm{v}^{-} 4 \mathrm{~T} 1$ cells were fixed with $1 \%$ formaldehyde, neutralized with $0.2 \mathrm{M}$ glycine, and suspended in a lysis buffer containing $10 \mathrm{mM}$ Tris- $\mathrm{HCl}$ (pH 8.0), $150 \mathrm{mM} \mathrm{NaCl}, 1 \%$ SDS, $1 \mathrm{mM}$ EDTA, and a protease inhibitor cocktail (Roche, Tokyo, Japan). The cell lysates were subjected to ultrasonic treatment (Sonifier 250; Branson, Kanagawa, Japan) and diluted with a solution containing $20 \mathrm{mM}$ Tris- $\mathrm{HCl}$ (pH 8.0), $150 \mathrm{mM} \mathrm{NaCl}, 1 \mathrm{mM}$ EDTA, and 1\% Triton $\mathrm{X}-100$ ) for immunoprecipitation with Protein A/G (Invitrogen)-bound antibodies to $\mathrm{H} 3 \mathrm{~K} 4 \mathrm{me} 3$ or to RNA polymerase II (both kindly provided by $\mathrm{H}$. Kimura) or with those to H3K27me3 (Merck, Tokyo, Japan). Precipitated DNA was prepared according to the Illumina/Solexa Genomic DNA protocol (Illumina, San Diego, CA). The DNA was amplified by PCR ( 18 cycles) with annealing to the flow cell of a Genome Analyzer. DNA fragments of 350 to $450 \mathrm{bp}$ were purified after separation on an agarose gel and diluted to $10 \mathrm{nM}$ for loading on the flow cell. The DNA library (2 pM) was applied to the flow cell with the use of the Cluster Station device (Illumina). ChIP sequencing (ChIP-seq) data were analysed, as described ${ }^{54}$. In brief, images acquired from the Illumina/Solexa sequencer were processed through the bundled Solexa image extraction pipeline, which identified Polony positions, performed base-calling, and generated quality control (QC) statistics. Sequences were aligned with the human genome in the NCBI genomic database (UCSC $\mathrm{mm} 9$ ) as the reference genome. Sequences that mapped uniquely to the genome with two-base mismatches were selected. Sequences from all lanes for each ChIP sample were combined, extended $200 \mathrm{bp}$ (maximum fragment length accounting for $\sim 100$ bp of primer sequence), and allocated into 25-bp bins. Genomic bins showing statistically significant ChIP-seq enrichment were identified by compari son with a Poissonian background model. For every 500-bp (for H3K4me3 and RNA polymerase II) or 1,000-bp (for $\mathrm{H} 3 \mathrm{~K} 27 \mathrm{me} 3$ ) window, the mapped tag count for the ChIP sample $\left(C_{\mathrm{c}}\right)$ and that for the ChIP input $\left(C_{\mathrm{i}}\right)$ were used for calculation. $E_{\mathrm{c}}$ and $E_{\mathrm{i}}$ represent the estimated counts for 500-bp windows for the ChIP sample and ChIP input, respectively. The signal ratio was calculated as $\left(C_{\mathrm{c}} / E_{\mathrm{c}}+1\right) / \operatorname{Max}(1$, $\left.C_{\mathrm{i}} / E_{\mathrm{i}}+1\right)$. These signals were visualized with Integrated Genome Browser software (Affymetrix, Santa Clara, CA, USA) ${ }^{55}$

Statistical analysis. Data are presented as means \pm s.d. and were analysed with the unpaired Student's $t$ test. A $P$-value of $<0.05$ was considered statistically significant

\section{References}

1. Weigelt, B., Peterse, J. L. \& van 't Veer, L. J. Breast cancer metastasis: markers and models. Nat. Rev. Cancer 5, 591-602 (2005).

2. Fidler, I. J. The biology of cancer metastasis. Semin. Cancer Biol. 21, 71 (2011).

3. Mehlen, P. \& Puisieux, A. Metastasis: a question of life or death. Nat. Rev. Cancer 6, 449-458 (2006).

4. Liu, H. et al. Cancer stem cells from human breast tumors are involved in spontaneous metastases in orthotopic mouse models. Proc. Natl Acad. Sci. USA 107, 18115-18120 (2010)

5. Chaffer, C. L. \& Weinberg, R. A. A perspective on cancer cell metastasis. Science 331, 1559-1564 (2011).

6. Croker, A. K. et al. High aldehyde dehydrogenase and expression of cancer stem cell markers selects for breast cancer cells with enhanced malignant and metastatic ability. J. Cell. Mol. Med. 13, 2236-2252 (2009).

7. Al-Hajj, M., Wicha, M. S., Benito-Hernandez, A., Morrison, S. J. \& Clarke, M. F. Prospective identification of tumorigenic breast cancer cells. Proc. Natl Acad. Sci. USA 100, 3983-3988 (2003).

8. Collins, A. T., Berry, P. A., Hyde, C., Stower, M. J. \& Maitland, N. J. Prospective identification of tumorigenic prostate cancer stem cells. Cancer Res. 65, 10946-10951 (2005).

9. Dalerba, P. et al. Phenotypic characterization of human colorectal cancer stem cells. Proc. Natl Acad. Sci. USA 104, 10158-10163 (2007).

10. Gunthert, U. et al. A new variant of glycoprotein CD44 confers metastatic potential to rat carcinoma cells. Cell 65, 13-24 (1991).

11. Yu, Q., Toole, B. P. \& Stamenkovic, I. Induction of apoptosis of metastatic mammary carcinoma cells in vivo by disruption of tumor cell surface CD44 function. J.Exp. Med. 186, 1985-1996 (1997).

12. Nagano, O. \& Saya, H. Mechanism and biological significance of CD44 cleavage. Cancer Sci. 95, 930-935 (2004).

13. Ponta, H., Sherman, L. \& Herrlich, P. A. CD44: from adhesion molecules to signalling regulators. Nat. Rev. Mol. Cell Biol. 4, 33-45 (2003). 
14. Warzecha, C. C., Sato, T. K., Nabet, B., Hogenesch, J. B. \& Carstens, R. P. ESRP1 and ESRP2 are epithelial cell-type-specific regulators of FGFR2 splicing. Mol. Cell 33, 591-601 (2009).

15. Screaton, G. R., Bell, M. V., Bell, J. I. \& Jackson, D. G. The identification of a new alternative exon with highly restricted tissue expression in transcripts encoding the mouse Pgp-1 (CD44) homing receptor. Comparison of all 10 variable exons between mouse, human, and rat. J. Biol. Chem. 268, 12235-12238 (1993).

16. Bennett, K. L. et al. CD44 isoforms containing exon V3 are responsible for the presentation of heparin-binding growth factor. J. Cell Biol. 128, 687-698 (1995).

17. Orian-Rousseau, V., Chen, L., Sleeman, J. P., Herrlich, P. \& Ponta, H. CD44 is required for two consecutive steps in HGF/c-Met signaling. Genes Dev. 16, 3074-3086 (2002)

18. Ishimoto, T. et al. CD44 variant regulates redox status in cancer cells by stabilizing the $\mathrm{xCT}$ subunit of system $\mathrm{xc}(-)$ and thereby promotes tumor growth. Cancer Cell 19, 387-400 (2011)

19. Chiang, A. C. \& Massague, J. Molecular basis of metastasis. N. Engl. J. Med. 359, 2814-2823 (2008).

20. Gupta, G. P. \& Massague, J. Cancer metastasis: building a framework. Cell 127, 679-695 (2006).

21. Granot, Z. et al. Tumor entrained neutrophils inhibit seeding in the premetastatic lung. Cancer Cell 20, 300-314 (2011)

22. Sato, H. et al. Redox imbalance in cystine/glutamate transporter-deficient mice. J. Biol. Chem. 280, 37423-37429 (2005)

23. Huang, Y., Dai, Z., Barbacioru, C. \& Sadee, W. Cystine-glutamate transporter SLC7A11 in cancer chemosensitivity and chemoresistance. Cancer Res. 65, 7446-7454 (2005)

24. Calvert, P., Yao, K. S., Hamilton, T. C. \& O’Dwyer, P. J. Clinical studies of reversal of drug resistance based on glutathione. Chem. Biol. Interact. 111-112, 213-224 (1998).

25. Goto, S. et al. Augmentation of transport for cisplatin-glutathione adduct in cisplatin-resistant cancer cells. Cancer Res. 55, 4297-4301 (1995).

26. Bannai, S. \& Ishii, T. Transport of cystine and cysteine and cell growth in cultured human diploid fibroblasts: effect of glutamate and homocysteate. J. Cell. Physiol. 112, 265-272 (1982).

27. Lo, M., Wang, Y. Z. \& Gout, P. W. The $\mathrm{x}(\mathrm{c})$ - cystine/glutamate antiporter: a potential target for therapy of cancer and other diseases. J. Cell. Physiol. 215 593-602 (2008)

28. Heppner, G. H., Miller, F. R. \& Shekhar, P. M. Nontransgenic models of breast cancer. Breast Cancer Res. 2, 331-334 (2000).

29. Ishimoto, T. et al. CD $44^{+}$slow-cycling tumor cell expansion is triggered by cooperative actions of Wnt and prostaglandin E2 in gastric tumorigenesis. Cancer Sci. 101, 673-678 (2010).

30. Motohara, T. et al. Transient depletion of p53 followed by transduction of c-Myc and K-Ras converts ovarian stem-like cells into tumor-initiating cells Carcinogenesis 32, 1597-1606 (2011).

31. Subramanian, A. et al. Gene set enrichment analysis: a knowledge-based approach for interpreting genome-wide expression profiles. Proc. Natl Acad. Sci. USA 102, 15545-15550 (2005).

32. Ben-Porath, I. et al. An embryonic stem cell-like gene expression signature in poorly differentiated aggressive human tumors. Nat. Genet. 40, 499-507 (2008).

33. Pawitan, Y. et al. Gene expression profiling spares early breast cancer patients from adjuvant therapy: derived and validated in two population-based cohorts. Breast Cancer Res. 7, R953-R964 (2005).

34. Kubo, A. et al. Semi-quantitative analyses of metabolic systems of human colon cancer metastatic xenografts in livers of superimmunodeficient NOG mice. Anal. Bioanal. Chem. 400, 1895-1904 (2011).

35. Morikawa, T. et al. Hypoxic regulation of the cerebral microcirculation is mediated by a carbon monoxide-sensitive hydrogen sulfide pathway. Proc. Natl Acad. Sci. USA 109, 1293-1298 (2012).

36. Griffith, O. W. \& Meister, A. Potent and specific inhibition of glutathione synthesis by buthionine sulfoximine (S-n-butyl homocysteine sulfoximine). J. Biol. Chem. 254, 7558-7560 (1979).

37. Diehn, M. et al. Association of reactive oxygen species levels and radioresistance in cancer stem cells. Nature 458, 780-783 (2009).

38. Ginestier, C. et al. ALDH1 is a marker of normal and malignant human mammary stem cells and a predictor of poor clinical outcome. Cell Stem Cell $\mathbf{1}$, 555-567 (2007).

39. Gout, P. W., Buckley, A. R., Simms, C. R. \& Bruchovsky, N. Sulfasalazine, a potent suppressor of lymphoma growth by inhibition of the $\mathrm{x}(\mathrm{c})-\mathrm{cystine}$ transporter: a new action for an old drug. Leukemia 15, 1633-1640 (2001).

40. Warzecha, C. C. et al. An ESRP-regulated splicing programme is abrogated during the epithelial-mesenchymal transition. EMBO J. 29, 3286-3300 (2010).

41. Yang, J. et al. Twist, a master regulator of morphogenesis, plays an essential role in tumor metastasis. Cell 117, 927-939 (2004).

42. Saint-Andre, V., Batsche, E., Rachez, C. \& Muchardt, C. Histone H3 lysine 9 trimethylation and HP1gamma favor inclusion of alternative exons. Nat. Struct. Mol. Biol. 18, 337-344 (2011).
43. Wagner, E. J. \& Carpenter, P. B. Understanding the language of Lys36 methylation at histone H3. Nat. Rev. Mol. Cell. Biol. 13, 115-126 (2012).

44. Guenther, M. G., Levine, S. S., Boyer, L. A., Jaenisch, R. \& Young, R. A. A chromatin landmark and transcription initiation at most promoters in human cells. Cell 130, 77-88 (2007).

45. Cao, R. et al. Role of histone H3 lysine 27 methylation in Polycomb-group silencing. Science 298, 1039-1043 (2002).

46. Klingbeil, P. et al. CD44 variant isoforms promote metastasis formation by a tumor cell-matrix cross-talk that supports adhesion and apoptosis resistance. Mol. Cancer Res. 7, 168-179 (2009).

47. Wallach-Dayan, S. B. et al. CD44-dependent lymphoma cell dissemination: a cell surface CD44 variant, rather than standard CD44, supports in vitro lymphoma cell rolling on hyaluronic acid substrate and its in vivo accumulation in the peripheral lymph nodes. J. Cell. Sci. 114, 3463-3477 (2001).

48. Pani, G., Galeotti, T. \& Chiarugi, P. Metastasis: cancer cell's escape from oxidative stress. Cancer Metastasis Rev. 29, 351-378 (2010).

49. Chen, R. S. et al. Disruption of xCT inhibits cancer cell metastasis via the caveolin-1/beta-catenin pathway. Oncogene 28, 599-609 (2009).

50. Brown, R. L. et al. CD44 splice isoform switching in human and mouse epithelium is essential for epithelial-mesenchymal transition and breast cancer progression. J. Clin. Invest. 121, 1064-1074 (2011).

51. Sahin, M., Sahin, E., Gumuslu, S., Erdogan, A. \& Gultekin, M. DNA methylation or histone modification status in metastasis and angiogenesisrelated genes: a new hypothesis on usage of DNMT inhibitors and Sadenosylmethionine for genome stability. Cancer Metastasis Rev. 29, 655-676 (2010).

52. Ishimoto, T. et al. CD $44^{+}$slow-cycling tumor cell expansion is triggered by cooperative actions of Wnt and prostaglandin E2 in gastric tumorigenesis. Cancer Sci. 101, 673-678 (2010).

53. Nagano, O. et al. Cell-matrix interaction via CD44 is independently regulated by different metalloproteinases activated in response to extracellular $\mathrm{Ca}^{2+}$ influx and PKC activation. J. Cell Biol. 165, 893-902 (2004).

54. Tozawa, H. et al. Genome-wide approaches reveal functional interleukin-4inducible STAT6 binding to the vascular cell adhesion molecule 1 promoter. Mol. Cell. Biol. 31, 2196-2209 (2011).

55. Nicol, J. W., Helt, G. A., Blanchard, S. G. Jr., Raja, A. \& Loraine, A. E. The integrated genome browser: free software for distribution and exploration of genome-scale datasets. Bioinformatics 25, 2730-2731 (2009).

\section{Acknowledgements}

We thank I. Ishimatsu, S.Suzuki, S.Hayashi, Y.Hata and K.Hizume for technical assistance; K.Arai for help in preparation of the manuscript. O.N. and H.S. are grateful to A.Izumi-Taguchi, T.Kodama (Lab for Systems Biology and Medicine, Research Center for Advanced Science and Technology, University of Tokyo, Meguro-Ku, Tokyo 153-8904, Japan), H.Ueda, T.Miyazawa, S.Yamamoto, K.Shiina and G.Nagae (Genome Science Division, Research Center for Advanced Science and Technology, University of Tokyo) for technical assistance in ChIP-sequencing analysis. Antibodies against Histone H3K4me3, Pol II were kindly provided by H.Kimura (Graduate School of Frontier Biosciences, Osaka University, Suita, Osaka 565-0871, Japan). This work was supported by grants from the Ministry of Education, Culture, Sports, Science, and Technology of Japan (to H.S.) as well as in part by the Project for Development of Innovative Research on Cancer Therapeutics (P-Direct), Ministry of Education, Culture, Sports, Science and Technology of Japan(to O.N.). Imaging mass spectrometry analysis was supported by Grant-in-Aid from the SENTAN Program from JST and Development of the NextGeneration Integrated Simulation of Living Matter, a Part of Development and Use of the Next-Generation Supercomputer Project of MEXT Japan.

\section{Author contributions}

H.S., K. Takahashi, and O.N. conceived the project and designed experiments. T.Y., K. Tsuchihashi, T.I., T. Motohara, M.Y., G. J. Y., T.W., T.O., Y.K., and A.K. performed experiments. T. Masuko, K.M., H.T., T. Minami, H.A., M.O. and M.S. analysed the data. H.S. and O.N. wrote the manuscript.

\section{Additional information}

Accession codes: The microarray data have been deposited in the GEO database under the accession code GSE35803.

Supplementary Information accompanies this paper at http://www.nature.com/ naturecommunications

Competing financial interests: The authors declare no competing financial interests

Reprints and permission information is available online at http://npg.nature.com/ reprintsandpermissions/

How to cite this article: Yae, T. et al. Alternative splicing of CD44 mRNA by ESRP1 enhances lung colonization of metastatic cancer cell. Nat. Commun. 3:883 doi: $10.1038 /$ ncomms1892 (2012). 